\title{
O EMPIRISMO CONSTRUTIVO DE BAS C. VAN FRAASSEN E O PROBLEMA DO SUCESSO CIENTÍ- FICO
}

\author{
Samuel Simon $(\mathrm{UnB})$ \\ samuell@unb.br \\ Aline Moraes (UnB) \\ aline_philo@yahoo.com.br
}

Resumo: $\mathrm{O}$ presente trabalho tem por objetivo apresentar os principais aspectos do Empirismo Construtivo de Bas C. van Fraassen, particularmente no que diz respeito ao problema do sucesso científico. Nesse contexto, serão examinadas as noções de observável e inobservável e suas relações com o "argumento do milagre" e da "coincidência cósmica", ambos criticados por van Fraassen. As respostas de autores que defendem o Realismo Científico serão então discutidas, contrapondo-se aos argumentos do Empirismo Construtivo. Finalmente, possíveis dificuldades do Empirismo Construtivo serão ainda analisadas e uma proposta para superá-las será apresentada, a partir de um estudo contemporâneo do papel da constante cosmológica na Teoria da Relatividade.

Palavras-chave: Van Fraassen, Realismo Científico, Sucesso Científico.

\section{INTRODUÇÃO}

A ciência empírica, particularmente suas teorias científicas, tem-se mostrado bem sucedida em suas explicações e previsões dos fenômenos ${ }^{1}$. Diante de tal panorama, realistas e anti-realistas científicos se opõem quanto à razão de tal sucesso. 
Para os realistas, o que justifica o sucesso científico é a existência de uma relação verdadeira (ou aproximadamente verdadeira) entre teorias científicas e o mundo. Os anti-realistas, por sua vez, defendem que não se pode afirmar que as teorias sejam verdadeiras, mas apenas buscam "salvar os fenômenos". Nesse contexto, as teorias são vistas não apenas como instrumentos de descrição, mas também como instrumentos de explicação ${ }^{2}$. Embora este último seja um aspecto importante do debate em torno do papel das teorias científicas, vamos nos concentrar no primeiro aspecto, ou seja, o problema do sucesso científico. Este tema não parece ter sido esgotado com as críticas anti-realistas, particularmente em relação aos chamados "argumentos do milagre", da "coincidência cósmica" e da "inferência para a melhor explicação”.

$O$ presente trabalho analisa a abordagem de Bas van Fraassen ao problema do sucesso científico. Para bem situar essa análise, será feita uma breve caracterização de sua doutrina por ele mesmo caracterizado como 'empirismo construtivo' (VAN FRAASSEN 2007, p. 24) -, conforme apresentado em A Imagem Científica ${ }^{4}$ e em suas obras posteriores. Um dos aspectos importantes desse empirismo é o tratamento dado à distinção entre "observável” e "inobservável”, os quais têm sido objeto de estudo de inúmeros filósofos da ciência e guardam estreita relação com o problema do sucesso científico. Este, por sua vez, se vincula a argumentos apresentados acima e caros aos realistas, objetos da crítica anti-realista. Para os realistas, esses argumentos - particularmente o do "milagre" ou da "coincidência cósmica" - são decisivos para explicar o sucesso científico. No entanto, para van Fraassen, o anti-realista não precisa temê-los. Segundo ele, o problema do sucesso científico esconde uma distinção entre características pragmáticas e epistêmicas, objeto de confusão do realista, o que invalidaria os 
argumentos. Na conclusão do presente trabalho, apontaremos alguns problemas dessa abordagem anti-realista.

\section{O EMPIRISMO CONSTRUTIVO DE BAS VAN FRAASSEN}

Uma das noções centrais no Empirismo Construtivo é a da adequação empírica. Van Fraassen apresenta uma definição precisa em A Imagem Científica:

Apresentar uma teoria é especificar uma família de estruturas, seus modelos; e, em seguida, especificar certas partes desses modelos (as subestruturas empíricas) como candidatas à representação direta dos fenômenos observáveis. As estruturas que podem ser descritas em relatos experimentais e de medição podemos chamar de aparências; a teoria é empiricamente adequada se possui algum modelo tal que todas as aparências sejam isomórficas à subestrutura empírica daquele modelo. (VAN FRAASSEN 2007, p. 122).

$\mathrm{Na}$ definição acima, o autor apresenta tanto os aspectos semânticos (da análise de teorias) quanto os aspectos empiristas. $\mathrm{O}$ aspecto semântico trata de entender uma teoria como uma família de modelos. $\mathrm{O}$ aspecto empirista preserva a exigência epistêmica, isto é, a teoria deve ser formada por modelos que pretendem ser representantes diretos dos fenômenos observáveis (subestrutura empírica). Assim, a teoria é empiricamente adequada se ela "salva os fenômenos" observáveis, ou seja, se um de seus modelos é isomórfico aos relatos experimentais e de medição (as aparências). Note-se que a adequação empírica de uma teoria só acontece mediante uma relação entre dois dos três modelos ${ }^{5}$ que compõem a teoria, isto é, a adequação empírica ocorre quando há uma relação de isomorfis- 
mo (parcial), entre subestrutura empírica e aparências (ou os modelos de dados, para ser mais exato).

Contudo, mesmo utilizando o termo "isomorfismo", van Fraassen não pretende que o conceito de adequação empírica seja entendido em termo de verdade por correspondência. $\mathrm{O}$ termo "isomorfismo" é usado num sentido geométrico ${ }^{6}$ para definir o conceito de adequação empírica, isto é, trata-se de uma noção geométrica que identifica a igualdade de formas entre modelos?

Diante disto, poderíamos concluir, de maneira apressada, que a aceitação de uma teoria científica, segundo o Empirismo Construtivo, se resumiria aos aspectos observáveis da mesma ou de sua consistência com os fatos. Todavia, de acordo com van Fraassen, a consistência com os fatos seria uma condição mínima para que uma teoria possa ser aceita (VAN FRAASSEN 2007, p. 170). Nestes termos, o critério de adequação empírica exige apenas o isomorfismo entre subestrutura empírica e aparências enquanto que o critério de verdade do realista exigiria, segundo o Empirismo Construtivo, um isomorfismo total entre todos os modelos da teoria e um compromisso com a existência de entidades inobserváveis. Em termos de uma abordagem semântica, estaríamos nos comprometendo com um isomorfismo exato entre todos os modelos da teoria e os modelos de dados.

Assim, se há isomorfismo entre os modelos teóricos (subestrutura empírica) e os modelos de dados, podemos afirmar, por extensão, que há isomorfismo também entre alguns 
modelos da teoria e os fenômenos observados. É desta maneira que dizemos que a teoria "salva os fenômenos". Como expressa van Fraassen, "[...] se uma estrutura pode representar os fenômenos, então também o pode qualquer estrutura isomórfica, mutatis mutandis" (VAN FRAASSEN 1997, p. 522). Todavia, ainda não podemos falar que ocorre, neste caso, uma adequação empírica definitiva por parte da teoria em relação com o mundo.

Como a todo o momento é possível o aparecimento de novos modelos de dados, a rigor, não podemos afirmar que uma teoria é empiricamente adequada de maneira definitiva; para que isso ocorresse, seria necessário que a subestrutura empírica fosse isomórfica não só com os modelos de dados do presente, mas também com os modelos de dados do futuro. Como nunca estamos em posse de teorias completas - teorias com todas as aparências à disposição - a crença na adequação empírica é tão arriscada quanto a crença na verdade ${ }^{8}$. Mas, mesmo assim, a crença na adequação empírica ainda parece, para o anti-realista, ser mais vantajosa que a crença na verdade, pois a primeira, segundo ele, estaria livre de considerações metafísicas ${ }^{9}$.

Desta maneira, podemos notar que a distinção entre verdade e adequação empírica, conforme a definição de van Fraassen, parece repousar numa segunda distinção, entre o que é observável e o que não é observável. 


\section{O PROBLEMA DA OBSERVABILIDADE EM VAN FRAASSEN}

A distinção entre observáveis e inobserváveis é um tema importante nos trabalhos de filósofos de orientação empirista.

Não seria diferente com o Empirismo Construtivo de van Fraassen. Ao adotar o conceito de adequação empírica, van Fraassen pretende desenvolver sua interpretação da ciência mantendo as exigências (ontológicas e epistemológicas) empiristas. No entanto, esse autor marca sua diferença com essa tradição: a distinção do que é observável e do que é inobservável é uma tarefa que compete à ciência e não a uma teoria filosófica ${ }^{10}$. Essa postura poderia conduzir a um internalismo ${ }^{11}$, mas van Fraassen o estima superável. Embora a "própria ciência delimita, pelo menos em alguma medida, as partes observáveis do mundo que ela descreve", a distinção entre observável e nãoobservável é "antropocêntrica”. Mas essa dificuldade é apenas aparente: "uma vez que a ciência coloca os observadores humanos entre os sistemas físicos que ela pretende descrever, ela mesma também se confere a tarefa de descrever distinções antropocêntricas" (VAN FRAASSEN 2007, p. 113).

Devido a esse posicionamento, van Fraassen termina por adotar uma postura naturalista, a qual gerou intensas críticas, sobretudo no que se refere a uma circularidade proveniente de tal naturalismo. Apresentaremos a seguir as críticas mais importantes.

A distinção entre observável e inobservável é antiga na filosofia da ciência e, de certa maneira, remonta à distinção en- 
tre corpóreo e incorpóreo dos estóicos. No período contemporâneo, o Empirismo Lógico retomou esse debate e gerou inúmeras críticas ao longo do século XX. Uma das mais célebres críticas foi feita por Grover Maxwell, apontada pelo próprio van Fraassen.

Em seu artigo "The Ontological Status of Theoretical Entities”, Maxwell parte da distinção entre termos observáveis e termos não-observáveis feita por Carnap no mesmo período. Neste artigo, Maxwell apresenta a tese do continuum da observação onde ressalta a impossibilidade da delimitação entre termos teóricos e não-teóricos e entre entidades observáveis e inobserváveis. De acordo com esse autor, não há uma distinção clara que possa dizer onde a observação acaba diante de uma seqüência de casos de observação como, por exemplo, olhar através de uma vidraça, olhar através de óculos, de binóculos, de um microscópio de baixa potência ou de alta potência, etc. A escolha de um ponto em que acaba a observação só pode ser feita por uma escolha arbitrária; do contrário, tal distinção entre observável e inobservável não será clara (MAXWELL 1962, p. 7).

Van Fraassen concorda com Maxwell, quanto à maneira como a distinção fora feita. No entanto, ele discorda da abordagem lingüística do Empirismo Lógico. Segundo van Fraassen, as expressões "entidade teórica" e "dicotomia observávelteórico", quando interpretadas literalmente, seriam exemplares de erro de categoria, na medida em que qualquer termo é sempre teórico, não se aplicando o predicado "observável" a termos lingüísticos. Contudo, a distinção entre entidades ob- 
serváveis e inobserváveis ainda pode ser feita. Quanto a isso, van Fraassen afirma que:

Termos ou conceitos são teóricos (introduzidos ou adaptados para as finalidades da construção de teorias); as entidades são observáveis ou inobserváveis. Isso parece de menor importância, mas divide a discussão em duas questões. Podemos dividir nossa linguagem em uma parte teórica e outra não-teórica? Por outro lado, podemos classificar os objetos e eventos em observáveis e inobserváveis? (VAN FRAASSEN 2007, p. 37)

Com relação à primeira questão, van Fraassen responde negativamente, pois admite, com Sellars e Feyerabend, que toda a nossa linguagem está contaminada por teorias. A segunda questão será respondida positivamente, opondo-se a Maxwell, que considera a distinção observável/inobservável arbitrária e pouco nítida. Contudo, van Fraassen busca mostrar que, mesmo sendo difícil apresentar uma definição exata de "observável”, ainda assim é possível identificar casos claros de observáveis. Para esse autor, a série de atos de observação não implica numa continuidade do que é observado. Se as luas de Júpiter podem ser vistas por um telescópio, podem também ser vistas a olho $\mathrm{nu}^{12}$, se estivermos próximo a elas. Todavia, ainda segundo van Fraassen, o mesmo não ocorre com relação às partículas atômicas, no caso da câmara de bolhas ${ }^{13}$. Vale notar que essa argumentação esconde um problema ao qual voltaremos, quando incluímos a matemática. Insistiríamos apenas que, nesse exemplo, o argumento não parece forte o suficiente para desqualificar Maxwell, pois, além de a teoria poder ter um avanço preditivo, propondo novas entidades - esse é um critério importante do realista científico -, o que não é observado 
num momento poderá vir a sê-lo num outro. Ou seja, a distinção observável/inobservável, nesses termos, é muito limitada, pois o próprio van Fraassen aceita - como vimos e ainda como veremos logo a seguir - que a ciência estipula o que é observável. Nesse sentido, a crítica de Maxwell permanece.

De acordo com van Fraassen, o que possibilita a distinção entre observáveis e inobserváveis é a própria condição do aparato sensível humano, assim como as condições do conhecimento em que se encontram as ciências ${ }^{14}$. Dessa maneira, mesmo sendo vaga qualquer tentativa de definição do que é observável, podemos identificar casos claros onde ocorre a observação. Os limites especiais da observabilidade são fornecidos pelas teorias que dispõem de elementos acessíveis aos sentidos dos seres humanos, isto é, os limites especiais derivam-se da constituição própria dos seres que fazem parte da nossa comunidade epistêmica.

Ian Hacking (1985, p. 135) apresenta uma crítica a essa distinção apontada acima. Para ele, van Fraassen acaba exigindo que o inobservável ganhe status de observável se ele puder ser visto a olho nu. Nesse caso, para o Empirismo Construtivo, de acordo com a interpretação de Hacking, as observações fornecidas por meio de um microscópio, seja ele óptico, seja ele eletrônico, não corresponderiam a observações genuínas, uma vez que não podemos observar os objetos mostrados pelo microscópio com a visão desamparada de instrumentos e, possivelmente, não seriam observações de entidades reais. 
Hacking apresenta ainda outras razões para não aceitar a distinção proposta por van Fraassen. Para Hacking, não podemos duvidar da existência das entidades inobserváveis relatadas em uma determinada teoria, uma vez que estas entidades podem ser detectadas e manipuladas por alguns instrumentos, embora insista que a crença na existência das entidades inobserváveis não implica na crença na verdade da teoria ${ }^{15}$. Assim, para defender a posição realista de entidades, segundo a qual, o que vemos nos microscópios corresponde a entidades reais, Hacking argumenta que a mesma entidade pode ser observada em mais de um instrumento ${ }^{16}$. Com isso, ele conclui que seria uma inexplicável coincidência que dois processos físicos diferentes fornecessem imagens visuais idênticas e, contudo, se tratassem não de entidades reais, mas de ilusões.

Van Fraassen argumenta, contrariamente a Hacking, que a concordância de imagens não se daria por meio da realidade das estruturas analisadas, isto é, por meio da existência efetiva das entidades inobserváveis, mas devido à mesma estrutura física inserida nos diferentes instrumentos, no caso do exemplo apresentado por Hacking, as amostras de sangue $^{17}$. Dessa forma, não teríamos nenhuma inferência fundamentada acerca da realidade da estrutura inobservável correspondente a essas amostras ${ }^{18}$.

Outra crítica à posição de van Fraassen é oferecida por Wilson (1985). Esse autor interpreta a posição de van Fraassen como internalista, isto é, todo conceito de observação é relativo a teorias. Dessa forma, os limites da observabilidade seriam relativos a uma determinada teoria; conseqüente- 
mente, haveria coisas observáveis para uma teoria, mas não para outra. Surgiria, dessa forma, uma circularidade viciosa, na medida em que uma teoria seria empiricamente adequada por apresentar-se isomórfica com os fenômenos observáveis. No entanto, o que é observável depende da própria teoria.

Giere (1985) também considera que a noção de observabilidade em van Fraassen enfrenta problemas de circularidade. Segundo Giere, ao deliberar à ciência a função de determinar o que é observável, van Fraassen privilegia ciências como a psicologia e a fisiologia ${ }^{19}$. De fato, já em um artigo de 1977, van Fraassen considera a abordagem de Sellars acerca da questão da percepção bastante aceitável: “[...] parece razoável pensar que a explicação oferecida por Sellars para a percepção tem exatamente a forma geral que esperaríamos que tivesse uma teoria da percepção na psicologia ou na fisiologia”. (VAN FRAASSEN 1977, p. 338). Desta maneira, se a fisiologia ou a psicologia são as únicas capazes de determinar a observabilidade, essas mesmas teorias determinariam seus próprios limites da observabilidade (GIERE 1985, p. 82 ss).

Van Fraassen não nega a existência de uma circularidade em sua posição, mas afirma que se trata de uma circularidade não viciosa:

Para delinear o que é observável, devemos examinar a ciência e possivelmente aquela mesma teoria -, pois isso também é uma questão empírica. Isso poderia gerar um círculo vicioso se aquilo mesmo que é observável fosse não simplesmente um fato 
revelado pela teoria, mas, ao contrário, algo relativo a teorias ou dependente delas. Ficará perfeitamente claro que nego isso; encaro o que é observável como uma questão independente de teorias. Trata-se de uma função de fatos sobre nós qua organismos no mundo, e esses fatos podem incluir aqueles sobre os estados psicológicos que envolvem a contemplação de teorias mas não há o tipo de dependência ou relatividade que pudesse causar aqui uma catástrofe lógica. (VAN FRAASSEN 2007, p. 111)

Dutra (1995, p. 153) considera essa circularidade apenas hermenêutica, tendo em vista que a própria teoria nos leva a descobrir os limites da observabilidade. Mas isso não impede, segundo esse autor, o problema da regressão ao infinito. Isto porque "a aceitação de uma teoria científica depende de uma noção de observabilidade dada por outra teoria científica, já aceita”. No entanto, “a aceitação dessa outra também depende de uma noção de observabilidade dada por uma terceira teoria científica, que teria de ter sido aceita antes, e assim por diante”.

Uma estratégia de evitar problemas como esse e mostrar como o naturalismo de van Fraassen apresenta uma circularidade hermenêutica e não viciosa é apresentada por Bourgeois (1987). De acordo com este autor, seriam teorias "de senso comum" que iniciariam a cadeia do processo aceitaçãodescoberta. Mas, ainda como observa Dutra (1995, p. 155), essa via não é autorizada pelo Empirismo Construtivo de van Fraassen. De toda maneira, a estratégia de Bourgeois, embora não autorizada, poderia ter sentido. Evidentemente, o senso comum poderia ser um limite possível, se não considerarmos mesmo que soe estranho -, as teorias científicas existentes. No entanto, examinando a prática científica, vemos que isso é ina- 
ceitável nos próprios termos de van Fraassen, pois uma subestrutura empírica não pode ter como domínio elementos oriundos do senso comum. E voltamos ao ponto inicial: no caso das ciências naturais, têm-se mensurações bem estabelecidas e dependentes de teorias e muitas vezes de inobserváveis. Essa dificuldade aponta exatamente para o Realismo Científico.

A oposição à formulação de van Fraassen em relação à distinção observável/inobservável feita pelo Realismo Científico considera que certos inobserváveis possam ser entidades reais. A estratégia dessa corrente fundamenta-se, sobretudo, no papel dos inobserváveis para o sucesso das teorias científicas. Ou seja, o realista pode defender a realidade das entidades inobserváveis, uma vez que o sucesso das teorias é considerado como uma forte evidência tanto para a verdade como para a existência dessas entidades. Diante disso, como um antirealista poderia explicar o sucesso científico, uma vez que eles não acreditam na verdade das teorias?

\section{O PROBLEMA DO SUCESSO DAS TEORIAS CIENTÍFICAS}

Segundo o instrumentalista, as teorias científicas são, no máximo, instrumentos eficazes, e não mais que isto, para explicar e predizer determinados fenômenos de maneira acurada. Contudo, para o realista a possibilidade de uma teoria ser bem sucedida em suas explicações e em suas predições acontece apenas se essa teoria corresponde, ao menos de maneira aproximada, ao mundo, tanto em suas conseqüências observáveis como em suas conseqüências inobserváveis. Seria inexplicável tal sucesso, caso a teoria se revelasse falsa. Este tipo de realis- 
mo, defendido por Sellars, Smart, Putnam, Boyd, dentre outros, afirma que as teorias são mais que meros instrumentos de predição ou explicação. Assim, as entidades e os processos inobserváveis relatados por essas teorias de sucesso provavelmente existem. Nesse contexto, segundo esses autores, somente a doutrina realista é capaz de oferecer uma explicação plausível à questão do sucesso das teorias científicas.

Putnam (1975), Smart (1963), Boyd (1984), dentre outros realistas, utilizam o famoso "argumento do milagre" ou da "coincidência cósmica" contra a doutrina anti-realista procurando defender a posição realista dos ataques anti-realistas ${ }^{20}$. Para o realista científico, o anti-realista não possui nenhuma explicação plausível para o sucesso instrumental das teorias científicas.

Na versão contemporânea, apresentada por Smart e Putnam, o "argumento do milagre" afirma basicamente o seguinte: se uma teoria científica consegue ser bem sucedida empiricamente, explicando uma variedade de fenômenos, então é muito improvável que esta teoria seja falsa e que as entidades e estruturas inobserváveis presentes nesta teoria não existam. É mais provável que esta teoria seja verdadeira ou ao menos aproximadamente verdadeira. Se essas entidades não existem e se a teoria é falsa, seria fruto de um milagre ou de uma grande coincidência cósmica que uma teoria falsa conseguisse predizer e explicar fenômenos de maneira acurada. Diante das alternativas, o realista prefere explicar o sucesso empírico de tais teorias por meio da atribuição de um valor de verdade (verdadeiro) a tais teorias, ou seja, "[...] sem assumir que a ciência des- 
creve o mundo real, seu sucesso seria um absoluto milagre" (CARRIER 1991, p. 23).

Dessa maneira, o realista procura não somente mostrar que a explicação do sucesso das teorias é satisfatória via uma interpretação realista, mas que o próprio Realismo Científico também se apresenta como uma doutrina verdadeira ou aproximadamente verdadeira pelo fato de ser a única doutrina capaz de explicar satisfatoriamente o sucesso científico. De acordo com Boyd, o realista estaria "[...] justificado porque ele oferece a melhor explicação científica para vários fatos sobre os modos pelos quais os métodos científicos são epistemicamente bem sucedidos" (BOYD 1984, p. 3). Para esse autor, a inferência realista, isto é, a conclusão da verdade aproximada de uma teoria por meio de seu alto poder explicativo de um fenômeno, não é algo pré-teórico (BOYD 1985); além disso, não existiria qualquer princípio epistemológico ou metodológico que não derive da ciência estabelecida. Desse modo, se temos na própria ciência o uso de inferências indutivas para explicar fenômenos da natureza, o epistemólogo estaria justificado a utilizar inferências indutivas.

O argumento que Boyd utiliza para defender essa tese é conhecido como o "inferência da melhor explicação" ou "inferência abdutiva". Esse argumento consiste em mostrar que um determinado raciocínio - no caso em questão, o Realismo Científico, assim como uma teoria científica - é autêntico ou que ele é portador de evidência para um determinado fenômeno se este raciocínio for a melhor explicação para o fenômeno em questão. Isto é, diante de um conjunto de evidências e de um 
conjunto de explicações, cabe à melhor explicação ser aproximadamente verdadeira. No entanto, o argumento abdutivo, assim como o "argumento do milagre" e da "coincidência cósmica”, usado pelos realistas tem sido questionado pelos filósofos anti-realistas contemporâneos.

Laudan (1981), por exemplo, observa que uma das dificuldades que o "argumento do milagre" apresenta é o fato de ele estar baseado na noção de verdade aproximada, para a qual os realistas não possuem uma definição precisa. Uma outra dificuldade para os realistas é, segundo Laudan, que a própria história da ciência não nos permite sustentar a tese realista. Teorias que foram bem sucedidas empiricamente na história da ciência se mostraram falsas e muitos termos teóricos que desempenhavam um importante papel na explicação de fenômenos, de fato, não denotavam ${ }^{21}$. Dessa maneira, "[...] o sucesso de uma teoria não é garantia para a afirmação de que a maior parte de seus termos centrais referem" (LAUDAN, 1981, p. 123) e, conseqüentemente, não seria seguro afirmar que tal teoria é, de fato, verdadeira ${ }^{22}$.

Outra crítica apresentada contra o argumento abdutivo é a que este leva em conta a própria natureza e justificação do argumento, pois, diferentemente do argumento dedutivo, a conclusão não seguiria necessariamente das premissas e depende de seu conteúdo. E o argumento abdutivo diferencia-se do indutivo por não necessariamente consistir na extensão uniforme da evidência. Dessa maneira, o argumento abdutivo utilizado pelo realista - a teoria que melhor explique um determinado fenômeno é uma teoria verdadeira, assim como o 
próprio Realismo Científico - parece exigir o critério da verdade de maneira antecipada ${ }^{23}$.

O principal problema deste tipo de argumento estaria na sua insuficiência em mostrar a verdade das premissas utilizadas. Um anti-realista como van Fraassen não aceita a conclusão de tal argumento, pelo motivo de não aceita, antecipadamente, a primeira premissa. Segundo esse autor, seria admissível apenas inferir a adequação empírica de uma teoria como a melhor explicação para o sucesso empírico da mesma.

Para van Fraassen, o argumento realista do sucesso empírico de teorias é uma inferência abdutiva. Isto é, se uma teoria científica se mostra como a melhor explicação de um fenômeno, deve-se crer pelo menos em sua verdade aproximada e, muito provavelmente, deve-se crer também na existência das entidades inobserváveis que a teoria postula. Para esse autor, o realista constata que usamos inferências abdutivas em diversos casos cotidianos e, se as adotamos consistentemente em todos os casos, seremos conduzidos ao Realismo Científico da maneira como a máxima de Sellars ${ }^{24}$ sugere.

Van Fraassen concorda que a regra abdutiva é e pode ser seguida nos contextos "ordinários". Todavia, ele discorda que tal regra nos leve a acreditar na existência de entidades inobserváveis bem como na verdade da teoria. $\mathrm{O}$ uso da regra abdutiva autoriza a tese realista, mas não proíbe a tese alternati$\mathrm{va}^{25}$. Nesse sentido, ele vê a posição realista - seguir regras abdutivas em contextos cotidianos - como uma hipótese psicológica acerca do que estamos dispostos ou não a fazer. 
Chegamos agora ao problema do sucesso no sentido forte, ou sucesso preditivo forte, como tem sido chamado na literatura $^{26}$, isto é, quando se trata de previsões de "fatos novos", ou quando uma teoria que é construída para explicar determinadas regularidades de fenômenos termina por prever novas regularidades conhecidas, mas não explicadas, ou então completamente desconhecidas.

No contexto da explicação e previsão de "fatos novos", Boyd (1984) e Musgrave (1985) apresentam uma reformulação do argumento do milagre com o intuito de torná-lo mais forte, evitando, dessa maneira, possíveis objeções anti-realistas. Boyd chama atenção à confiabilidade preditiva de uma teoria científica. Para esse autor, há casos de predições de fenômenos que são inteiramente diferentes do domínio de fenômenos que a teoria a princípio havia sido formulada e que se mostra surpreendentemente bem sucedida. Boyd conclui que, nestes casos, somente um apelo à idéia de milagre seria uma alternativa a uma explicação realista acerca do sucesso da ciência (BOYD, 1984, p. 49). Semelhantemente à argumentação de Boyd, Musgrave também considera que a confiabilidade preditiva de uma teoria com relação aos fenômenos que estão, em princípio, fora do domínio fenomênico em que a teoria foi construída, mostra-se como uma forte evidência da verdade da teoria em questão. Musgrave estabelece, assim, a relação direta com o argumento do milagre:

É, porém, diferente se uma teoria projetada para acomodar algumas regularidades fenomênicas prediga novas regularidades. O realista tem uma explicação pronta: as entidades postuladas 
pela teoria realmente existem, e o que a teoria diz sobre elas é verdadeiro (ou aproximadamente verdadeiro). $\mathrm{O}$ anti-realista parece ser forçado a dizer que ficções inventadas para um determinado propósito milagrosamente mostram-se bem adaptadas para um propósito muito diferente. (MUSGRAVE 1985, p. 210).

Várias teorias da física aparecem como exemplares dessa capacidade de prever "fatos novos" 27 . Outros filósofos da ciência já haviam considerado a questão dos "fatos novos" como uma noção forte de sucesso empírico (ver, por exemplo, Laka$\operatorname{tos}^{28}$ (1970) e Leplin (1984)). No entanto, Carrier (1991) lembra corretamente que Whewell, já no século XIX, havia notado a importância dos "fatos novos" para o argumento realista do sucesso empírico. Nesse sentido, Whewell (1858) estima que:

Nenhum exemplo pode ser apontado, em toda a história da ciência, até onde eu sei, no qual esta "consiliência de induções" tenha dado testemunho em favor de uma hipótese que posteriormente descobríssemos ser falsa. Se tomarmos uma classe de fatos isoladamente, sabendo a lei a qual eles seguem, podemos construir uma hipótese, ou talvez várias, que possa representálos; e, quando uma nova circunstância for descoberta, poderemos sempre ajustar as hipóteses de modo que corresponda a ela também. Mas quando a hipótese, por si mesma e sem ajustamentos para este fim, nos fornece as regras e razões de uma classe não prevista em sua construção, nós temos um critério de sua realidade, o qual ainda não foi produzido em favor de sua falsidade. (WHEWELL apud CARRIER 1991, p. 26).

Leplin (1997) considera como um critério suficiente para sustentar as teses realistas o fato de uma teoria fazer predições adequadas que se mostram novas com respeito ao contexto de aplicação em que esta foi construída. $\mathrm{O}$ anti-realista poderia 
defender que, se uma teoria que é construída para explicar um conjunto de regularidades fenomênicas e se esta teoria as explica e, além disso, é capaz de prever fenômenos correlacionados a ela, então não se configuraria de maneira alguma um milagre que tal teoria seja bem sucedida empiricamente. Poderia, até mesmo, ser explicado tal sucesso empírico sem o comprometimento com a noção de verdade como pretende o realista. Contudo, quando a teoria é capaz de prever fenômenos que não estão relacionados diretamente com a formulação da teoria, o sucesso empírico não pode ser explicado sem a suposição da verdade, ou verdade aproximada, da mesma ${ }^{29}$.

Vejamos a seguir a resposta de van Fraassen ao problema do sucesso científico entendido em seu sentido forte, examinando o argumento de Smart acerca da "coincidência cósmica”.

\section{LIMITES DA EXIGÊNCIA POR EXPLICAÇÕES}

Para van Fraassen, a regra da inferência para a melhor explicação apenas permite a inferência realista, mas não a obriga. E o argumento realista só estará completo se houver um comprometimento com a verdade de uma das hipóteses, cuja aplicação explicaria a evidência. Caso contrário, a regra abdutiva não conduziria ao Realismo.

Mas como o anti-realista opta por escolher hipóteses do tipo que afirmem não a verdade, mas a adequação empírica da teoria, o realista, segundo van Fraassen, precisará de uma outra premissa para que o argumento realista esteja completo, isto é, que todas as regularidades da natureza necessitam de explica- 
ç̃es ilimitadas ${ }^{30}$. Isto conduz, de acordo com o empirista construtivista, à postulação de entidades inobserváveis, como encontramos na argumentação de Smart, Salmon, Sellars e outros.

Contudo, para van Fraassen, o sucesso preditivo de uma teoria pode ser explicado pelo fato de a teoria corresponder (em termos semânticos) aos fenômenos observáveis. Mas, o realista, nos diz van Fraassen, não se limita a tal explicação e quer explicar as regularidades fenomênicas em termos de uma estrutura mais profunda, do contrário restaria a crença em coincidências em escala cósmica ${ }^{31}$. Diante de tal argumento, esse autor procura mostrar alguns motivos pelos quais o empirista construtivista não precisa concordar com o realista.

Primeiramente, ao admitir um limite para a demanda por explicações, van Fraassen recorre à tradição nominalista ${ }^{32}$. Em conformidade com essa concepção, as regularidades no mundo (as predições bem sucedidas da ciência, por exemplo), não sendo mais que fatos brutos, não demandam explicações. Dessa forma, o anti-realista pode evitar a postulação de entidades e processos subjacentes aos fenômenos observáveis, detendo assim o argumento realista. Mas, mesmo se fosse permitido uma explicação, a postulação de entidades inobserváveis seria irrelevante para a compreensão do mundo, assim como para a própria adequação empírica da teoria ${ }^{33}$.

O segundo motivo que o empirista construtivista apresenta para não aceitar o argumento realista é direcionado a refutar a afirmação de Smart acerca da "coincidência cósmica". 
O fato de um evento ter ocorrido (no caso a predição de um fenômeno por uma teoria que não foi construída para o âmbito do fenômeno em questão) não implica que ele não possa ser explicado, ou que possa ser explicado somente da maneira realista. Van Fraassen argumenta utilizando o seguinte exemplo: ainda que eu encontre, de maneira fortuita, um conhecido em um mercado, poderia ser oferecido uma explicação desse fato (possivelmente existiriam razões para ambos estarem neste mercado e, em virtude disso, o encontro aconteceu) mesmo não sendo planejado ${ }^{34}$.

Desse modo, pode-se dizer que van Fraassen tenta dissolver o problema e nos apresenta três razões pelas quais o problema do sucesso científico não mereceria explicações por parte do anti-realismo - principalmente por parte do Empirismo Construtivo.

A primeira razão vincula-se à própria explicação realista do sucesso científico, isto é, no uso do argumento do milagre e da inferência da verdade para a melhor explicação. Para van Fraassen, a estrutura de tais argumentos exibiriam uma circularidade e não conseguiriam demonstrar a verdade das premissas, ou seja, de que o sucesso científico só pode ocorrer caso as teorias se revelassem verdadeiras.

A segunda razão estaria na adoção de uma posição nominalista: as regularidades do mundo - assim como o sucesso científico - compreendidas à maneira nominalista, como meros fatos brutos, não demandariam explicações. 
A terceira razão imporia um limite para a demanda por explicações: não se exigiria explicações que extrapolassem as regularidades observáveis. Dessa maneira, ainda para van Fraassen, teorias empiricamente adequadas podem ser falsas, no que diz respeito ao aspecto subjacente aos fenômenos observáveis, mas ainda assim se revelariam extremamente bem sucedidas.

Para o Empirismo Construtivo, as características relevantes que envolvem a questão do sucesso científico são características pragmáticas e não epistêmicas e dizem respeito ao poder explicativo de teorias - traço presente nas teorias bem sucedidas. Nesse sentido, van Fraassen oferece uma teoria pragmática da explicação científica, procurando deter os argumentos realistas baseados no poder explicativo. A teoria pragmática da explicação científica demanda um estudo detalhado, que será objeto de um outro trabalho.

\section{CONCLUSÃO}

As críticas de van Fraassen ao Realismo Científico suscitam alguns problemas ${ }^{35}$. O primeiro, vincula-se à suposta inexistência de um conceito de verdade aproximada das teorias científicas, postulado por essa corrente filosófica. Essa crítica é bastante discutível, pois, além do fato de alguns filósofos da ciência - como Niiniluoto (2002) e Da Costa e French (2003) terem proposto importantes desenvolvimentos em relação a essa noção, não há por que negá-la a priori. O Realismo Científico estaria, assim, imune a essa crítica. 
O segundo problema vincula-se ao uso da noção de isomorfismo entre modelos (de dados e da subestrutura empírica) para justificar a adequação empírica, em contraposição às concepções do Empirismo Lógico, criticada por van Fraassen. Essa noção, bem definida na teoria dos modelos (HUNTER, 1996, p. 201), depende de uma fórmula em uma linguagem axiomatizada $^{36}$. Ou seja, a exigência do positivismo lógico de axiomatização de teorias reaparece na noção de isomorfismo, pois, para que haja uma interpretação, necessitamos de uma fórmula, oriunda de uma teoria axiomatizada.

O terceiro problema vincula-se à crítica que "o realista exige que todas as regularidades da natureza exigem explicações”, o que, segundo van Fraassen, é refutado pelo nominalismo e pelo instrumentalismo, pois as regularidades seriam "fatos brutos". Ora, a busca de explicações é uma das exigências da própria ciência, o que significa encontrar uma causa ( $a$ posteriori), o que a ciência tem feito, sobretudo a partir do período moderno, apesar de todas as dúvidas lançadas pelos empiristas. Assim, um naturalismo ao estilo daquele preconizado pelo próprio van Fraassen para os observáveis responderia a essa crítica. Quando o realista busca uma explicação para o sucesso da ciência, nada mais faz do que seguir os cientistas. Nesse sentido, críticas como a de Hacking são pertinentes. Em exemplos como o uso do microscópio para examinar amostras de sangue, van Fraassen pode ter dificuldades em sua argumentação (ver acima, nota 14). O que se observa nos aparelhos são as estruturas moleculares, que podem ser "vistas" em dife- 
rentes aparelhos. Essa é a argumentação de Hacking, a qual van Fraassen não parece ter uma resposta adequada.

O último problema é axiológico. Assim como o Realismo Científico, o Empirismo Construtivo é uma tese metafísica, nos termos em que ambos têm se apresentado ${ }^{37}$. São estudos filosóficos - fundados em argumentos lógicos, históricos, sociológicos - de como as teorias científicas (e muitas vezes extrapolam-se, indevidamente, para toda atividade científica) relacionam-se com os fenômenos, ou com os dados empíricos, para sermos mais exatos. E sendo uma tese metafísica - de como o mundo é ou do que posso falar (ou não) dele -, ambas as correntes têm dificuldades em muitos aspectos.

Nesse sentido, defendemos uma mudança de perspectiva: a tese realista, seja um realismo de entidades, seja um realismo de teorias, deve ser considerada de um ponto de vista metodológico e não como uma hipótese psicológica, como pretende van Fraassen (ver acima). A história da ciência tem mostrado que os próprios cientistas adotam a tese realista como uma maneira de superar dificuldades teóricas ou experimentais, de expandir as teorias científicas, de buscar relações entre fenômenos antes sem conexão, de testar experimentalmente ou teoricamente as relações entre os conceitos e os fenômenos ou apenas estritamente entre conceitos, como no caso da Matemática ${ }^{38}$.

O sucesso científico entendido no sentido forte, no contexto de "fatos novos", é um dos fundamentos do trabalho científico. Tomemos um exemplo bastante contemporâneo, ainda não devidamente explorado pelo realismo científico: a 
constante cosmológica. Essa constante tem uma história plena de ensinamentos. Einstein a postulou admitindo um universo estático, tendo em vista que ela é possível no contexto das soluções da equação da teoria da relatividade geral e necessária para tal universo (estático). No entanto, com a descoberta da expansão do universo, Einstein a abandonou, considerando-a seu "maior erro" em física. Hoje ela é um divisor de águas na cosmologia, pois essa constante é admitida em certas equações para explicar a expansão do universo e não há razões a priori para eliminá-la - ou seja, apesar de Einstein tê-la abandonado, ela voltou à Física. Tendo em vista seu valor extremamente pequeno, muitos físicos consideram que deva ser abandonada, enquanto outros a consideram bem-vinda em oposição a certas formas de energia, como a energia escura, que seria responsável pela repulsão da matéria, se consideramos essa constante nula. Vale notar que ambas as propostas são empiricamente adequadas nos domínios de validade da cosmologia atual e, portanto, não será esse o critério para decidir pela manutenção ou não da constante, mas sim sua inserção em outras teorias.

Esse nos parece um caso exemplar: um inobservável orienta a pesquisa científica em vários domínios científicos, nesse caso a própria cosmologia e a física de partículas. Além do mais, em certo sentido, ela pode ser real, pelo menos tão real quanto o valor constante da velocidade da luz no vácuo, a constante de Planck, entre outras, para ficar apenas no domínio da Física. Conceitos como esses mantêm-se na mudança científica - não são abandonados quando novas teorias são propostas -, mas estão presentes em casos limites destas e mui- 
tas vezes são pontos de partida importante para desenvolvimentos futuros, como a constante de gravitação newtoniana, fundamental para a Teoria da Relatividade Geral.

Esse exemplo anterior - o da constante cosmológica mostra o quanto os inobserváveis não são apenas objetos de adequação empírica, embora sejam empiricamente adequados, pois podem ser oriundos de uma investigação eminentemente teórica (isso sem recorrer a inúmeros exemplos da Matemática) e orientam a pesquisa em várias direções. Os chamados "fatos novos", que classificaríamos no domínio da descoberta científica, e que se inserem no âmbito do sucesso científico no sentido forte, nos parecem longe de um simples resultado de adequação empírica no sentido do Empirismo Construtivo. $\mathrm{O}$ Realismo Científico pode, assim, configurar-se como uma postura metodológica (mesmo que em bases metafísicas).

A analogia utilizada por van Fraassen para contestar o "argumento do milagre", o encontro casual de duas pessoas num mercado, está longe de representar a atividade científica. As teorias são conjuntos de modelos que buscam explicar ou representar $^{39}$ certos tipos de fenômenos, propriedades, relações, etc. E os "fatos novos" podem fundamentar um realismo ao menos moderado (aproximado), pois esses fatos são incorporados pelas teorias, após um longo processo de atividade científica, e não são resultado de um mero fruto do acaso.

Abstract: This paper aims to present the main aspects of Bas C. van Fraassen's constructive empiricism, particularly regarding the problem of scientific success. In this way, the conceptions of the observable and the unobservable and their relations with the arguments 'of miracle' 
and 'cosmic coincidence', both criticized by van Fraassen, will be examined. The answers by authors who defend scientific realism will then be presented, as a counterpoint to the arguments of constructive empiricism. In the end, some more possible difficulties of constructive empiricism will be analyzed and a proposal to surpass them will be presented.

Keywords: Van Fraassen, Scientific Realism, Scientific Success.

\section{NOTAS}

1. Voltaremos a esses aspectos ao longo do presente trabalho. No entanto, vale notar que o termo "previsão" tem mais de um significado em filosofia da ciência: refere-se seja a fatos já conhecidos, seja a "fatos novos" (que classificaríamos como uma das formas mais importantes de descoberta científica), decorrentes de uma nova teoria, desconhecidos antes da existência da teoria.

2. O problema da explicação é analisado por van Fraassen no capítulo 5 de A Imagem Científica (utilizaremos aqui a tradução de Luiz Henrique Dutra à obra The Scientific Image), onde ele apresenta uma teoria pragmática da explicação. Para van Fraassen, há uma separação entre ciência pura e ciência aplicada, sendo a explicação reservada apenas à segunda. Mas, como afirmamos acima, esse aspecto, embora importante, não será examinado no presente trabalho.

3. Não há acordo na literatura que o "argumento do milagre" e da "coincidência cósmica" sejam ambos o mesmo argumento. No entanto, para os nossos propósitos, vamos aderir à tese da equivalência entre os dois, como fazem alguns autores, pois isso não alterará nossas conclusões, como será visto. 
4. Embora esse não seja o primeiro trabalho filosófico de van Fraassen, ele é considerado a obra inaugural do seu Empirismo Construtivo.

5. Os modelos seriam três, pois existiria ainda a superestrutura empírica, que seriam os modelos mais gerais que conteriam as subestruturas. No entanto, van Fraassen não especifica esses modelos.

6. Segundo Dutra, "van Fraassen apela para a noção geométrica de isomorfismo, e diz que duas estruturas são isomórficas se elas se encaixam uma na outra perfeitamente" (2001, p. 58). O uso que van Fraassen faz da noção de isomorfismo será examinado na conclusão do presente artigo.

7. "Dizemos que uma estrutura pode se encaixar em outra se a primeira é isomórfica a uma parte (uma subestrutura) da segunda. $\mathrm{O}$ isomorfismo é, obviamente, a identidade total de estrutura, e é um caso limite da encaixabilidade; se duas estruturas são isomórficas, então cada uma delas pode se encaixar na outra”. (VAN FRAASSEN 2007, p. 87)

8. van Fraassen reconhece essa dificuldade: "Nos dois casos, arriscamos o pescoço; a adequação empírica vai muito além do que podemos saber em qualquer tempo dado. (Todos os resultados de medição nunca são incluídos; eles nunca vão estar todos incluídos; e, em qualquer caso, não vamos medir tudo aquilo que pode ser medido)". (VAN FRAASSEN 2007, p. 129)

9. "Entretanto, há uma diferença: a afirmação da adequação empírica é muito mais fraca que a afirmação da verdade, e nos restringimos à aceitação nos livra da metafísica”. Ibid. Quando ele fala de metafísica ele se refere, evidentemente, às teses realistas. 
10. Se há limites para a observação, eles são assuntos para a ciência empírica, e não para uma análise filosófica. E também, esses limites não podem ser descritos de uma vez por todas, assim como a medição não pode ser descrita de uma vez por todas. [...] Para encontrar os limites do que é observável no mundo descrito pela teoria $\mathrm{T}$, devemos perguntar à própria $\mathrm{T}$ e às teorias utilizadas como auxiliares no teste e na aplicação de T." (VAN FRAASSEN 2007, p. 110).

11. Voltaremos a essa questão logo mais. Ver página 82.

12. Não vamos examinar agora os problemas desse exemplo, ao qual voltaremos a seguir, pois privilegiar os observáveis via sensações, como faz van Fraassen, pode trazer inúmeras dificuldades. Para o empirista-construtivo, alguém privado da visão teria que afirmar que as luas de Júpiter são inobserváveis.

13. "Olhar as luas de Júpiter através de um telescópio me parece ser um caso claro de observação, uma vez que, sem dúvida, os astronautas vão ser capazes de vê-las também de perto. Mas a suposta observação de micropartículas em uma câmara de vapor me parece um caso claramente diferente - se estiver correta nossa teoria sobre o que ali acontece. A teoria diz que, se uma partícula carregada atravessa uma câmara preenchida com vapor saturado, alguns átomos nas vizinhanças de sua trajetória são ionizados. Se esse vapor é descomprimido e, portanto, se se torna supersaturado, ele condensa em gotículas onde estão os íons, criando assim a trajetória da partícula. A linha cinza-prata resultante é similar (fisicamente, assim como em aparência) à trilha de vapor deixada no céu quando um jato passa. Suponhamos que eu aponte tal trilha e diga: "olhe, lá está um jato!”Alguém poderia dizer: "vejo a trilha de vapor, 
mas onde está o jato?" Então, eu responderia: "olhe logo à frente da trilha,... lá! Você o vê?” Ora, no caso da câmara de vapor, essa resposta não é possível. Assim, apesar de ser a partícula detectada por meio da câmara de vapor, e essa detecção estar baseada em observação, claramente, esse não é um caso de estar a partícula sendo observada”. (VAN FRAASSEN 2007, p. 41)

14. Vale ressaltar que os observáveis, em cada um desses casos, podem ser fundalmente diferentes, pois, no caso da ciência, pode envolver instrumentos de medidas e não apenas o aparato sensível humano.

15. "But one can believe in some entities without believing in any particular theory in which they are embedded. One can even hold that no general deep theory about the entities could possibly be true, for there is no such truth". (HACKING 1983, p. 29).

16. Para exemplificar sua abordagem, Hacking diz que a mesma imagem dos corpos densos das células vermelhas do sangue podem ser vistos tanto por transmissão eletrônica quanto por reemissão fluorescente (HACKING 1985, p. 146).

17. "But no one doubts that it is in each case blood samples and not different kinds of physical systems that were fed into the machines. This conclusion warrants no inference about the reality of the imputed unobservable structure". (VAN FRAASSEN 1985, p. 298).

18. Voltaremos, na Conclusão, a essa crítica de Hacking.

19. "The correct approach, he suggests, is not through philosophical analysis or armchair psychology but through the empirical study of human perceptual capabilities. So determining what is observable depends on scientific theory, but on psychology and physiology, not on physics. [...] But 
is very difficult to see how the study of human perceptual capabilities could tell us that velocity is observable while mass is not." (GIERE 1985, p. 81-82).

20. De acordo com Chibeni (1997, p. 22-3), o "argumento do milagre" ou da "coincidência cósmica" teria sido antecipado por Descartes nos Principes de la philosophie.

21. "Now, what the history of science offers us is a plethora of theories which were both successful and (so far as we can judge) non-referential with respect to many of their central explanatory concepts. I discussed earlier one specific family of theory which fits description. Let me add a few more prominent examples to the list:

the crystalline spheres of ancient and medieval astronomy;

the humoral theory of medicine;

the effluvial theory of static electricity;

…

the electromagnetic ether;

This list, which could be extended ad nauseam, involves in every case a theory which was once successful and well confirmed, but which contained central terms which (we now believe) were non-referring". (LAUDAN 1981, p. 122-3).

22. Essa conhecida argumentação de Laudan não será objeto do presente artigo. Observaríamos apenas que muitos dos exemplos que Laudan apresenta não são genuínas teorias científicas, mas hipóteses auxiliares ou mesmo modelos icônicos que buscavam fundar uma teoria científica.

23. Essa é, basicamente, a crítica feita por Bueno (1999), que retoma van Fraassen, como veremos a seguir. Para Bueno, o "argumento do milagre" possui uma estrutura seme- 
lhante a dos argumentos transcendentais. Chibeni (2006) rebate esse tipo de crítica. Não vamos repetir aqui os argumentos de Chibeni, com os quais concordamos. Basicamente, sua resposta mostra que o filósofo realista, diferentemente do cientista, não está buscando explicações dos fenômenos.

24. "Ter boas razões para sustentar uma teoria é, ipso facto, ter boa razão para sustentar que as entidades postuladas pela teoria existem." (SELLARS 1962, p. 97).

25. "[...] logical rule is a rule of permission (modus pones allows you to infer $B$ from $A$ and (if $A$ then B), but does not forbid you to infer (B or A) instead)". (VAN FRAASSEN 2007, p. 47)

26. Cf. Carrier, 1991.

27. Leplin (1997) apresenta uma análise histórico-filosófica detalhada de um grande número exemplos de "fatos novos".

28. Lakatos parece ter sido o primeiro a retomar, no século XX, a importância dos "fatos novos" como um elemento para determinar um domínio científico. No entanto, sua insistência não mereceu a devida atenção da comunidade dos filósofos da ciência.

29. "[...] Novel success is the exception to the antirealist strategy of proliferating explanations of success; it cannot be explained without crediting the theory that achieves it with some measure of truth". (LEPLIN 1997, p. 37)

30. Em seu artigo "Against transcendental Empiricism", van Fraassen analisa os "alvos" da crítica empirista, que são as concepções metafísicas. Essas concepções, em primeiro lugar, dão primazia à exigência ilimitada por explicações e, em segundo lugar, necessitam de explicações por postula- 
ção (explicações que postulam entidades inobserváveis). (VAN FRAASSEN 1994)

31. Esta conclusão de van Fraassen é apoiada pela seguinte passagem de Smart: "O realista (diria) [...] que o sucesso de T' é explicado pelo fato de que a teoria original $\mathrm{T}$ é verdadeira a respeito das coisas sobre as quais pretensamente ela diz respeito, em outras palavras, pelo fato de que realmente há elétrons ou o que quer que seja postulado pela teoria $T$. Se tais coisas não existem, e se $T$ não fosse verdadeira de uma forma realista, o sucesso de T’ não seria completamente inexplicável? Ter-se-ia de supor que há inúmeros acidentes felizes sobre o comportamento mencionado no vocabulário observacional, de tal maneira que eles se dessem miraculosamente como se fossem produzidos pelas coisas pretensamente não-existentes sobre as coisas das quais se fala no vocabulário teórico." (SMART apud VAN FRAASSEN 2007, p. 54)

32. "Dos debates medievais, evocamos a resposta nominalista de que as regularidades básicas são regularidades meramente brutas, e que não têm qualquer explicação. Assim, aqui, o anti-realista, de forma semelhante, deve dizer: os fenômenos observáveis exibem essas regularidades porque o fato de se ajustarem eles à teoria é meramente um fato bruto, e pode ou não ter uma explicação em termos de fatos inobserváveis "por trás dos fenômenos" - isso realmente não importa para a teoria ser boa, nem para nossa compreensão do mundo”. (VAN FRAASSEN 2007, p. 53)

33. É importante observar que van Fraassen adota uma posição agnóstica acerca das entidades inobserváveis e não uma posição cética, ou seja, as entidades inobserváveis são entendidas como ficções que podem ou não existir. Van Fraassen não afirma que elas não existam; nesse sentido, 
ele não pode ser considerado um cético a esse respeito. E a abordagem semântica de teorias, numa perspectiva empirista construtivista, não impede a existência de outros modelos, além daqueles que procuram ser representantes dos fenômenos observáveis, a subestrutura empírica.

34. "Foi por coincidência que encontrei um amigo no mercado - mas posso explicar por que eu estava lá, e ele pode explicar por que ali foi; assim, juntos, podemos explicar como se deu esse encontro. Nós o chamamos de coincidência não porque o acontecimento seja inexplicável, mas porque não foi para nos encontrarmos que cada um de nós foi ao mercado. Não pode haver uma exigência de que, com suas teorias, a ciência elimine as coincidências, ou as correlações acidentais em geral, pois isso nem mesmo faz sentido. Não há nada nisso que possa motivar a exigência de explicações, mas apenas uma reiteração em termos mais persuasivos". (VAN FRAASSEN 2007, p. 55)

35. As críticas apresentadas aqui na Conclusão merecem uma investigação mais detalhadas. No entanto, configuram-se como dificuldades que nos parecem importantes no Empirismo Construtivo de Bas van Fraassen e que devem ser apontadas.

36. "A model of a formula of a language is an interpretation of the language for which the formula comes out true". HUNTER 1996, p. 6.

37. Como vimos acima, van Fraassen fala da "crença" antirealista.

38. Num artigo recente (SIMON 2008), um dos autores mostrou que a formulação central de van Fraassen, o de adequação empírica, é bastante problemática, pois, a rigor, exclui a matemática do domínio da ciência. 
39. Evidentemente, os conceitos de representação e explicação são bastante complexos em filosofia da ciência e serão examinados num próximo trabalho, no contexto da teoria pragmática da explicação de van Fraassen.

\section{REFERÊNCIAS}

BOURGEOIS, W. On rejecting Foss's image of van Fraassen. Philosophy of science, 54, p. 303-308, 1987.

BOYD, R. The current status of scientific realism. In: LEPLIN, J. (org). Scientific realism. Berkeley: University of California Press, 1984, p. 41-82.

. Lex orandi est lex credendi. In: CHURCHLAND, P. M.; HOOKER, (org.). Images of science. Essays on realism and empiricism, with a reply from Bas C. van Fraassen. Chicago: The University of Chicago Press, 1985, p. 3-34.

BUENO, O. O Empirismo Construtivo: uma reformulação e defesa. Campinas: UNICAMP, 1999.

CARRIER, M. What is wrong with the miracle argument? Studies in history and philosophy of science, 1, p. 23-36, 1991.

CHIBENI, S. "Afirmando o conseqüente: uma defesa do realismo científico”. Scientiae studia, 4 (4): 221-249, 2006.

.Aspectos da descrição física da realidade. Campinas: Unicamp, 1997.

CHURCHLAND, P. M.; HOOKER, (org.). Images of science. Essays on realism and empiricism, with a reply from Bas C. van Fraassen. Chicago: The University of Chicago Press, 1985. 
DA COSTA, N. e FRENCH, S. Science and Partial Truth. Oxford: Oxford University Press, 2003.

DUTRA, L. H. Verdade e investigação: o problema da verdade na teoria do conhecimento. São Paulo: EPU, 2001.

- A distinção observável/inobservável no Empirismo Construtivo de van Fraassen. In: CARVALHO, M. A filosofia analítica no Brasil. Campinas: Papirus, 1995, p. 143-158.

GIERE, R. N. Constructive realism. In: CHURCHLAND, P; HOOKER, (org.). Images of science. Essays on realism and empiricism, with a reply from Bas C. van Fraassen. Chicago: The University of Chicago Press, 1985, p. 75-98.

HACKING, I. Representing and intervening. Cambridge: Cambridge University Press, 1983.

- Do we see through a microscope? In: CHURCHLAND, P. M.; HOOKER, (org.). Images of science. Essays on realism and empiricism, with a reply from Bas C. van Fraassen. Chicago: The University of Chicago Press, 1985, p. 132-152.

HUNTER, G. Metalogic: An Introduction to the Metatheory of Standard First Order Logic. Berkeley: University of California Press, 1996.

LAKATOS, I. and MUSGRAVE, A.. Criticism and the Growth of Knowledge, Cambridge: Cambridge University Press, 1970.

LEPLIN, J. (org). Scientific realism. Berkeley: University of California Press, 1984. 
. A novel defense of scientific realism. Oxford: Oxford University Press, 1997.

LAUDAN, L. A confutation of convergent realism. In: PAPINEAU. The philosophy of science, 1996, p. 107-138, 1981.

MAXWELL, G. The ontological status of theoretical entities. In: FEIGL, $\mathrm{H}$ and MAXWELL, G (org.). Scientific explanation, space and time. Minnesota studies in philosophy of science, vol. 3, Minneapolis: University of Minnesota Press, 1962, p. 3-27.

MUSGRAVE, A. Realism vs. constructive empiricism. In: CHURCHLAND, P. M.; HOOKER, (org.). Images of science. Essays on realism and empiricism, with a reply from Bas C. van Fraassen. Chicago: The University of Chicago Press, 1985. p. 197-221.

NIINILUOTO, I. Critical Scientific Realism. Oxford, clarendon Library, 2002.

PUTNAM, H. Mathematics, matter and method. Philosophical Papers, Vol 1, Cambridge: Cambridge University Press, 1975.

SELLARS, W. The language of theories. Science, perception, and reality. London: Routledge and Kegan Paul, 1962.

SIMON, S. "Empirical Adequacy and Scientific Discovery", Principia, 12, 2008.

SMART, J.J.C. Philosophy and scientific realism. New York: Routledge \& Kegan Paul/The Humanities Press, 1963.

VAN FRAASSEN, B. C. On the radical incompleteness of the manifest image (comments on Sellars). In: SUPPE, F.; 
ASQUITH, P. PSA (Philosophy of Science Association, East Lansing), vol. II, 1977, p. 335-343.

. The scientific image. Oxford: Claredon

Press, [1980]. Trad. Luiz Henrique Dutra. A Imagem Científica. São Paulo: Editora UNESP/Discurso Editorial, 2007.

- Empiricism in the philosophy of science. In: CHURCHLAND; HOOKER (org.). Images of science: essays on Realism and Empiricism, whit a reply by Bas C. van Fraassen. Chicago: University of Chicago Press, 1985.

. Against transcendental empiricism. In: STAPLETON (org.), The questions of hermeneutics. Dordrecht: Kluwer, 1994, p. 309-335.

. "Structure and perspective: philosophical perplexity and paradox". In: DALA, C (org), Logic and scientific methods. Dordrecht: Kluwer, 1997, p. 511-530. WILSON, M. What can theory tell us about observation? In: CHURCHLAND, P. M.; HOOKER, (org.). Images of science. Essays on realism and empiricism, with a reply from Bas C. van Fraassen. Chicago: The University of Chicago Press, 1985, p. 222-242. 